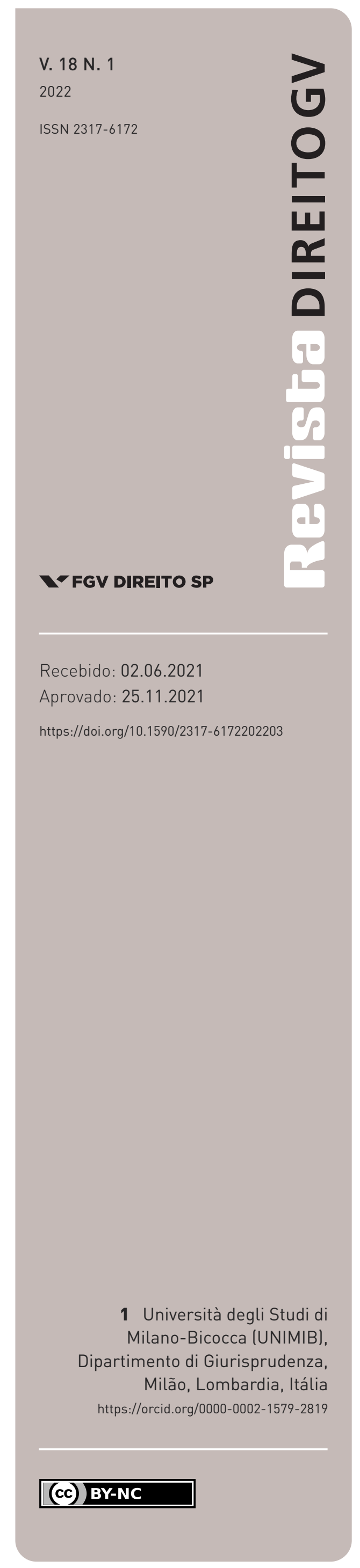

\section{A APLICAÇÃO DOTRATADO INTERAMERICANO DE ASSISTÊNCIA RECÍPROCA (TIAR) À CRISE VENEZUELANA DE 2019}

\author{
THE APPLICATION OF THE INTER-AMERICAN TREATY OF RECIPROCAL ASSISTANCE (TIAR) TO \\ THE VENEZUELAN CRISIS OF 2019 \\ Bernardo Mageste Castelar Campos ${ }^{1}$
}

\section{Resumo}

Este artigo trata da aplicação do Tratado Interamericano de Assistência Recíproca (TIAR) à situação interna da Venezuela em 2019 após a adesão do país por solicitação do autointitulado governo interino da Assembleia Nacional Venezuelana (ANV). É analisada a compatibilidade da aplicação do TIAR pela ANV e pelo Órgão de Consulta com o direito internacional. Em especial são examinadas as possibilidades de aplicação do TIAR aventadas no caso venezuelano pelo exercício da legítima defesa coletiva ou em razão da existência de "fato ou situação que possa pôr em perigo a paz de América", bem como as hipóteses de intervenção armada e medidas coercitivas como medidas passíveis de serem adotadas no caso em questão, tais quais as sanções efetivamente adotadas pelo Órgão de Consulta em setembro e dezembro de 2019. A metodologia empregada para análise é normativa, feita com base nas normas do TIAR, interpretadas segundo seu objetivo, trabalhos preparatórios e prática subsequente das partes, além de normas do direito internacional geral. Conclui-se que o emprego do TIAR no caso em questão e a adoção de eventuais medidas coercitivas nele baseadas são contrários ao direito internacional em razão da inexistência de hipóteses normativas válidas no instrumento que justifiquem sua aplicação à situação concreta.

\section{Palavras-chave}

Tratado Interamericano de Assistência Recíproca; segurança coletiva; legítima defesa coletiva; intervenção; uso da força.

\begin{abstract}
The article deals with the application of the Inter-American Treaty of Reciprocal Assistance (TIAR) to the Venezuelan crisis of 2019 following its accession at the request of the self-titled interim government of the Venezuelan National Assembly (ANV). The purpose of the article is to analyse the compatibility with international law of the application of the TIAR by the ANV and the Organ of Consultation. In particular, the hypothesis of application of the TIAR raised in the Venezuelan case are examined in relation to the exercise of collective self-defence or the existence of "a fact or situation that could endanger the peace of America". The application of coercive measures, such as the sanctions adopted by the Organ of Consultation in September and December 2019, and the possibility of armed intervention are also analysed. The methodology adopted is normative, based on the provisions of the TIAR, interpreted according to its objective, preparatory works and subsequent practice of the parties, in addition to general rules of international law. It is concluded that the use of the TIAR and the adoption of coercive measures based on it are contrary to international law due to the lack of valid normative hypotheses in the treaty that justify its application to the specific situation.
\end{abstract}

\section{Keywords}

Inter-American Treaty of Reciprocal Assistance; collective security; collective selfdefence; intervention; use of force. 


\section{INTRODUÇÃO}

Em agosto de 2019 a Organização dos Estados Americanos (OEA) aceitou o pedido de adesão da Venezuela ao Tratado Interamericano de Assistência Recíproca (TIAR) feito pelo autointitulado governo interino estabelecido pela Assembleia Nacional Venezuelana (ANV), seis anos após o país denunciar o instrumento. À primeira vista não são evidentes as razões pelas quais o TIAR, instrumento criado em 1947 com a função primordial de servir de mecanismo de proteção recíproca dos países do continente americano contra ameaças externas, poderia ser utilizado para a superação dos problemas internos venezuelanos.

A invocação do TIAR pela Venezuela levanta a questão da compatibilidade da utilização do Tratado como mecanismo de solução de questões predominantemente domésticas com o direito internacional, uma vez que as hipóteses de emprego estão previstas em seus arts. $3^{\circ} \mathrm{e}$ $6^{\circ}$. Sua utilização fora desses propósitos, assim, excederia os limites legais.

O presente artigo se dispõe a analisar juridicamente a utilização do TIAR no caso específico da Venezuela, em especial se a aplicação do Tratado pela ANV ou pelo Órgão de Consulta é compatível com o direito internacional. Serão consideradas as hipóteses de aplicação alegadas e as medidas coletivas que poderão ser tomadas com base no instrumento, bem como as medidas adotadas pelo Órgão de Consulta em 23 de setembro e 3 de dezembro de 2019.

A primeira parte do trabalho analisa as hipóteses de aplicação do TIAR previstas no instrumento original que poderiam ser aplicadas no caso concreto ou que foram consideradas até o momento, como é o caso do exercício da legítima defesa coletiva e a existência de riscos à paz regional. A segunda parte analisa as medidas específicas que em vista da existência de hipóteses de aplicação podem ser utilizadas para obstá-las, sendo consideradas as hipóteses de intervenção militar e a adoção de medidas coercitivas que não utilizam a força armada, como as adotadas pelo Órgão de Consulta nos últimos meses de 2019. Ao final são traçadas algumas reflexões sobre as conclusões obtidas.

\section{HiPóteses de APLICAÇÃo do Tratado}

O recurso às medidas previstas no TIAR é condicionado à existência de situações específicas e excepcionais de ameaça à paz regional. Seu principal cenário de aplicação, previsto no art. $3^{\circ}$, se refere à existência de um ataque armado contra um Estado americano, o que, pelo assim chamado princípio da solidariedade continental, obriga os Estados-partes do Tratado a auxiliar o Estado vítima de acordo com o direito à legítima defesa coletiva. $\mathrm{O}$ TIAR estabelece ainda três outras hipóteses de utilização que resultem em risco a um Estado americano mas que não configuram o exercício da legítima defesa coletiva, sendo elas a existência de "uma agressão que não seja um ataque armado", de um "conflito armado extracontinental ou intracontinental" ou de "qualquer outro fato ou situação que possa pôr em perigo a paz de América” (art. $6^{\circ}$ ). Apenas o exercício da legítima defesa coletiva e a última das três hipóteses foram alegados no caso concreto. Nesta sessão, analisam-se 
as duas hipóteses verificando de que maneira elas poderiam ou não se configurar na atual situação da Venezuela.

\section{I. EXERCÍCIO DA LEGÍTIMA DEFESA COLETIVA}

O TIAR surgiu como resultado do desejo dos países americanos de estabelecer um tratado regional para lidar com ameaças ou atos de agressão após a Segunda Guerra Mundial, e por isso tem como pedra angular o exercício da legítima defesa coletiva por seus Estados-partes (CASTILLA, 1948, p. 126). Seu art. $3^{\circ}$ determina que

[a]s Altas Partes Contratantes concordam em que um ataque armado, por parte de qualquer Estado, contra um Estado Americano, será considerado como um ataque contra todos os Estados Americanos e, em consequência, cada uma das ditas Partes Contratantes se compromete a ajudar a fazer frente ao ataque, no exercício do direito imanente de legítima defesa individual ou coletiva que é reconhecido pelo Artigo 51 da Carta das Nações Unidas.

$\mathrm{O}$ art. $3^{\circ}$ permitiria à Venezuela solicitar a utilização dos mecanismos de auxílio existentes no TIAR em razão da interferência externa indevida em seu território. A existência de uma interferência externa é expressamente alegada pela Exposição de Motivos da Lei Venezuelana incorporadora do TIAR, a qual afirma que

[...] existem evidências de ingerência militar estrangeira indevida nos assuntos internos da Venezuela, que, juntamente com o colapso progressivo do Estado venezuelano, diminuíram a capacidade das Forças Armadas Nacionais [...] e, especificamente, [de] garantir o uso legítimo da força em todo o território nacional na presença de organizações criminosas paraestatais no país. (VENEZUELA, 2019, p. 12, tradução nossa) ${ }^{\mathbf{1}}$

Tal "ingerência militar estrangeira” poderia caracterizar a violação do princípio da não intervenção nos assuntos domésticos venezuelanos, mas o exercício da legítima defesa não se justifica sem a existência efetiva de um ato de força armada. A existência de um ataque armado é considerada um requisito elementar para o exercício da legítima defesa tanto pelo art. $3^{\circ}$ do TIAR quanto pela Carta das Nações Unidas e pelo direito internacional consuetudinário

1 “...] existen pruebas de la indebida injerencia militar extranjera en asuntos domésticos venezolanos, lo que aunado al progresivo colapso del Estado venezolano, ha mermado la capacidad de la Fuerza Armada Nacional [...] y en concreto, de asegurar el legítimo uso de la fuerza en todo el territorio nacional ante la presencia de organizaciones criminales paraestatales en el país [...].” 
(BROWNLIE, 1963, p. 365). Dessa forma, no caso em questão parece não existir elementos suficientes para justificar o exercício da legítima defesa coletiva.

Por outro lado, a atividade de “organizações criminosas paraestatais” em território venezuelano poderia fazer referência à hipótese de agressão indireta, hipótese na qual um Estado auxilia efetivamente e controla grupos armados, irregulares ou rebeldes no território de outro Estado com efetivo uso da força mesmo que ausentes confrontos diretos entre as forças armadas dos dois países (BROWNLIE, 1963, p. 369). Nessa hipótese admite-se que o Estado vítima solicite o auxílio de outros Estados para lidar com tais grupos em seu próprio território, mas ainda assim se faz necessário que os atos de uso da força perpetrados por tais organizações criminosas sejam equivalentes a um ataque armado.

Essa foi a conclusão alcançada pela Corte Internacional de Justiça (CIJ) no caso Nicarágua (1986). Ao analisar a alegação dos Estados Unidos de que o uso da força no território da Nicarágua fora realizado no exercício da legítima defesa coletiva contra a agressão indireta cometida pelo país centro-americano contra Honduras e El Salvador, a CIJ entendeu que,

[n]o caso da legítima defesa individual, o exercício desse direito está sujeito ao fato de o Estado em questão ter sido vítima de um ataque armado. A invocação da legítima defesa coletiva evidentemente não elimina a necessidade disso. [N]o direito consuetudinário a proibição de ataques armados pode ser aplicada ao envio por um Estado de bandos armados para o território de outro Estado, se tal operação, devido à sua escala e efeitos, puder ser classificada como um ataque armado e não como um mero incidente de fronteira caso tivesse sido realizado por forças armadas regulares. (CIJ, 1986, p. 103, tradução nossa) $)^{2}$

A CIJ rejeitou o argumento dos Estados Unidos ao entender que o fornecimento de armas ou outras formas de auxílio a forças armadas irregulares poderia constituir a violação dos princípios da proibição do uso da força e da não intervenção, mas não possuía a gravidade suficiente para caracterizar um ataque armado para fins do exercício da legítima defesa coletiva (CIJ, 1986, p. 127). Dessa forma, atos de mera "ingerência militar" ou o apoio geral a grupos armados não seriam suficientes para justificar o exercício da legítima defesa em favor da Venezuela.

2 "In the case of individual self-defence, the exercise of this right is subject to the State concerned having been the victim of an armed attack. Reliance on collective self-defence of course does not remove the need for this. [...] in customary law, the prohibition of armed attacks may apply to the sending by a State of armed bands to the territory of another State, if such an operation, because of its scale and effects, would have been classified as an armed attack rather than as a mere frontier incident had it been carried out by regular armed forces." 
Outra hipótese de exercício da legítima defesa coletiva relacionada a atividades de grupos armados parece ter sido implicitamente reconhecida pelo Órgão de Consulta do TIAR, o qual, em sua Resolução aprovada em 23 de setembro de 2019, manifesta que

[...] o território venezuelano, com a complacência do regime ilegítimo, se tornou um refúgio de organizações terroristas e grupos armados ilegais, como o Exército de Libertação Nacional, Grupos Armados Organizados Residuais, e outros, que ameaçam a segurança do continente, violando as obrigações estabelecidas na Resolução 1373 de 2001 do Conselho de Segurança das Nações Unidas. (tradução nossa) ${ }^{3}$

A decisão do Órgão de Consulta afirma expressamente ter o território venezuelano se tornado um refúgio seguro para atividades terroristas em violação à referida Resolução $n$. 1373 do Conselho de Segurança das Nações Unidas (CSNU). A Resolução n. 1373 estabelece a obrigação dos Estados de não auxiliarem de nenhuma forma atividades terroristas e adotarem medidas para prevenir e punir tais atividades, tendo sido utilizada por alguns países para justificar o uso da força em exercício da legítima defesa preventiva contra o território de países onde operam organizações terroristas (RATNER, 2013, p. 334). ${ }^{4}$

Apesar de sua eventual invocação por alguns países ocidentais, a hipótese de legítima defesa contra países que abrigam ou auxiliam terroristas não encontra respaldo no direito internacional pelo fato de que a existência de um ataque armado prévio é considerada um requisito para o exercício da legítima defesa (ARCARI, 2018, p. 307). Da mesma forma a legítima defesa contra grupos armados internos não é admitida pelo direito internacional em razão da ausência de um ataque originado por outro Estado. Em sua Opinião Consultiva sobre o Muro em Território Palestino Ocupado, a CIJ rejeitou a possibilidade de utilização da Resolução n. 1373 para justificar o exercício da legítima defesa contra grupos armados internos ou outras ameaças originadas em territórios controlados pelo Estado que a invoca (CIJ, 2004, p. 194).

A legítima defesa individual ou coletiva é um direito dos países que admite diferentes maneiras de aplicação, não se limitando a hipóteses de intervenções armadas estrangeiras diretas no Estado vítima e podendo ser exercida em seu próprio território contra ameaças

3 “ $[\ldots]$ the Venezuelan territory has, with the complacency of the illegitimate regime, become a refuge of terrorist organizations and illegal armed groups, such as the National Liberation Army, Residual Organized Armed Groups, and others, which threaten the security of the continent, in violation of the obligations established in Resolution 1373 of 2001 of the United Nations Security Council.”

4 Este foi o argumento utilizado pelos Estados Unidos para justificar a intervenção militar no Afeganistão em outubro de 2001, sob a alegação de que as operações da Al Qaeda em território afegão contavam com a permissão do Talibã. 
externas mediante sua solicitação. Seu exercício, no entanto, só pode ser feito mediante a existência do uso da força com certa gravidade e que tenha sua origem em outro Estado (CORTEN, 2010, p. 304). No cenário existente na Venezuela em 2019 tais requisitos parecem não existir, motivo pelo qual o exercício da legítima defesa coletiva a pedido da ANV não seria lícito.

\section{I.2. EXISTÊNCIA DE "FATO OU SITUAÇÃo QUE POSSA PÔR EM PERIGO A PAZ DE AMÉRICA"}

O uso do TIAR não se limita à hipótese do exercício da legítima defesa, podendo ser aplicado a outras hipóteses que justifiquem a ação coletiva de seus Estados-partes. O Projeto de Lei da ANV não menciona especificamente o exercício da legítima defesa coletiva, mas a "indevida ingerência militar estrangeira em assuntos domésticos venezuelanos” e o "progressivo colapso do Estado venezuelano" são descritos como causas que podem "pôr em perigo a paz da América devido aos efeitos regionais do colapso do Estado venezuelano" (VENEZUELA, 2019, p. 12), às quais o TIAR ofereceria soluções. A hipótese descrita pelo Projeto utiliza expressamente o texto do art. $6^{\circ}$ do TIAR, o qual prevê que:

\section{Artigo $6^{\circ}$}

Se a inviolabilidade ou integridade do território ou a soberania ou independência política de qualquer Estado Americano for atingida por uma agressão que não seja um ataque armado, ou por um conflito extracontinental ou intracontinental, ou por qualquer outro fato ou situação que possa pôr em perigo a paz de América, o órgão de Consulta reunir-se-á imediatamente a fim de acordar as medidas que, em caso de agressão, devam ser tomadas em auxílio do agredido, ou, em qualquer caso, convenha tomar para a defesa comum e para a manutenção da paz e da segurança no Continente. (grifo nosso)

Ao identificar as condições existentes na Venezuela como circunstâncias que podem pôr em perigo a paz da América, o Projeto de Lei estabelece que a crise interna venezuelana poderia ser capaz de acionar os mecanismos presentes no TIAR em razão da disseminação de seus efeitos para os países vizinhos e em razão da perturbação da segurança e da paz regionais, tornando o problema uma questão que não afeta somente a Venezuela, mas todo o continente. Esse entendimento foi adotado também pelo Órgão de Consulta do TIAR, o qual, em sua Resolução de 23 de setembro de 2019, considerou que atividades criminosas imputadas a membros do governo de Nicolás Maduro e a crise humanitária existente no país "representam uma ameaça à manutenção da paz e segurança do continente, sob os termos do artigo 6 do Tratado Interamericano de Assistência Recíproca”, o que foi reiterado na Resolução de 3 de dezembro de 2019.

O enquadramento da situação interna venezuelana como uma ameaça à manutenção da paz e da segurança do continente pelo Órgão de Consulta foi criticado pelo representante do Uruguai, o qual ressaltou que 
[o] Tratado não foi projetado para lidar em conjunto com conflitos políticos internos ou ameaças internas à segurança nacional de qualquer Estado americano em particular. A invocação do artigo 6 do TIAR abre caminho para a intervenção armada em um país da região por outro país ou outros países da região, e isso claramente contraria o espírito e a letra do artigo, que pretendia defender as Américas de agressões externas e não permitir agressões internas. (tradução nossa) ${ }^{\mathbf{5}}$

Os termos vagos do texto do TIAR não impedem a priori que questões predominantemente domésticas de um Estado possam ser consideradas ameaças à paz regional por seu Órgão de Consulta, a quem o Tratado atribuiu o poder de determinar a caracterização das hipóteses de sua aplicação pela ausência à época de um conceito internacional definido de ato de agressão ou ataque armado (GARCIA-MORA, 1951, p. 9). O mesmo acontece na prática do CSNU, que não raramente caracteriza situações predominantemente internas como crises humanitárias, perseguições à população civil, golpes de Estado e a geração de fluxos de refugiados como ameaças à paz internacional (STROMSEHT, BROOKS e WIPPMAN, 2006, p. 32). ${ }^{6}$ As similaridades entre os poderes discricionários do CSNU e do Órgão de Consulta do TIAR, contudo, são bastante limitadas. As competências e as funções dos dois órgãos no sistema internacional de segurança coletiva são diversas, gozando o CSNU de poderes mais extensos e predominância na manutenção da paz e da segurança internacionais. Já os limites de aplicação do TIAR estão circunscritos à adoção de medidas coletivas tomadas durante o exercício da legítima defesa coletiva e a ameaças à paz continental, havendo sempre em suas hipóteses de aplicação um elemento de exterioridade das ameaças. Esse elemento evidencia a intenção dos Estados-partes de criar um mecanismo de ação militar coletiva para evitar um isolamento regional (ROCHA e LE CHAFFOTEC, 2015, p. 4)

5 "The Treaty was not designed to jointly deal with internal political conflicts or internal threats to any particular American state's national security. Invoking Article 6 of the TIAR paves the way for armed intervention in one country of the region by another country or other countries of the region, and this clearly runs contrary to the spirit and letter of the article, which was intended to defend the Americas from external aggressions and not to enable internal aggressions."

6 Os membros do CSNU adotaram posições divergentes em relação à Venezuela nos quatro encontros realizados em 2019 dedicados ao tema. A situação humanitária venezuelana foi expressamente considerada uma ameaça à paz e à segurança regionais por Alemanha, Bélgica, Estados Unidos, Peru, Polônia e Reino Unido, enquanto África do Sul, China, Guiné Equatorial e Rússia rejeitaram a classificação, e Costa do Marfim, Indonésia e República Dominicana adotaram um posicionamento neutro. O Grupo de Lima, formado em 2018 por doze países americanos para discutir a crise venezuelana, considerou em fevereiro de 2019 que o governo de Nicolás Maduro representava "uma ameaça sem precedentes à segurança, à paz, à liberdade e à prosperidade em toda a região”, mas não mencionou a crise humanitária como razão para tal consideração. 
e é ressaltado pelo Preâmbulo do TIAR, que atribui ao Tratado o objetivo primordial de "assegurar a paz por todos os meios possíveis, prover auxílio recíproco efetivo para enfrentar os ataques armados contra qualquer Estado Americano, e conjurar as ameaças de agressão contra qualquer deles".

A preocupação em lidar com ameaças externas é evidenciada também em seus trabalhos preparatórios. ${ }^{7}$ Hipóteses de aplicação do Tratado diversas de ataques ou atos de agressão não foram previstas inicialmente nos estudos preparatórios do Comitê Jurídico Interamericano ou nas discussões da Conferência Interamericana para a Manutenção da Paz e da Segurança no Continente de 1947 (EUA, 1948, p. 172). ${ }^{8}$ O termo "outro fato ou situação que possa pôr em perigo a paz de América” foi adotado para servir de cláusula geral que abrangesse as diversas propostas feitas pelos países participantes da Conferência para descrever situações que não configurassem propriamente ataques armados. A maioria das propostas fazia referência a outros tipos de atos de agressão e ameaças passíveis de serem lidadas com ação coletiva (EUA, 1948, p. 25). A existência de conflitos ou ameaças internas que pudessem afetar a paz na região não foi discutida. Ao contrário, o princípio da não intervenção foi ressaltado em diversas ocasiões, como nas propostas feitas pelas delegações da Colômbia, Panamá, Bolívia, Equador, Argentina e Venezuela (EUA, 1948, p. 69).

A prática do Órgão de Consulta também é um importante indicativo dessa interpretação. A crise venezuelana de 2019 foi a primeira vez em que o Órgão considerou uma situação como ameaça à paz e à segurança continentais sem identificar a existência do elemento externo que afetasse a independência ou soberania política de um Estado americano.

Dentre as quatro ocasiões em que o art. $6^{\circ}$ foi acionado com base em situações que representavam ameaças à paz e à segurança continentais (suposto envolvimento do governo da República Dominicana na tentativa de assassinato do presidente venezuelano Rómulo Betancourt, combate à "contínua intervenção de poderes Sino-Soviéticos" na América em relação à aproximação do governo cubano com a União Soviética em janeiro de 1962, conflitos transfronteiriços entre Costa Rica e Nicarágua em 1978 e a Guerra das Malvinas), apenas as ações tomadas contra Cuba em 1962 se referem a uma situação doméstica. Ainda assim, a forma como o Órgão de Consulta tratou a questão cubana é ilustrativa para compreender como a função do TIAR é entendida pela prática de seus Estados-partes. À época

7 A hipótese também está ausente na Declaração sobre Assistência Mútua e Solidariedade Americana (ou Ata de Chapultepec), firmada em março de 1945 ao final da Conferência Interamericana sobre Problemas da Guerra e da Paz. A Declaração recomendou a celebração de um tratado americano de assistência recíproca e foi o ponto de partida para a elaboração do TIAR.

8 Sobre a influência do Comitê Jurídico Interamericano na codificação do direito nas Américas, veja Lima (2019). 
o Órgão entendeu que a adoção da ideologia comunista por Cuba teria se originado não da livre escolha do país, mas da ingerência soviética na ilha, justificando a utilização do art. $6^{\circ}$ do TIAR e a adoção de medidas coletivas contra o país em razão da "ofensiva comunista” e da “ofensiva subversiva de governos comunistas” na América (OEA, 1962a). De forma diversa da questão venezuelana, o emprego doTIAR contra circunstâncias políticas internas de Cuba foi justificado com base na existência de um elemento externo ao país que afetasse sua independência, e não como uma questão doméstica, sendo o princípio da não intervenção reiterado no encontro (OEA, 1962c).

A inexatidão dos termos empregados no art. $6^{\circ}$ do TIAR oferece uma ampla possibilidade de situações em que o tratado pode ser empregado, o que em tese também poderia abarcar hipóteses de conflitos ou crises internas que ameacem a segurança regional. Tais hipóteses, no entanto, devem ser compreendidas dentro dos objetivos do TIAR de servir como um instrumento de coordenação no caso de ataque contra Estados americanos. Em relação a tais objetivos, o TIAR pode ser compreendido sob duas perspectivas distintas. Comparado a outros instrumentos de organizações regionais, o TIAR é um típico tratado de assistência recíproca que estabelece mecanismos para o exercício da legítima defesa coletiva, tendo funções limitadas em relação à manutenção da segurança regional. Dessa forma, hipóteses de aplicação que não se relacionam com o exercício da legítima defesa contra ataques armados ou outras ameaças externas não estão abarcadas pelo Tratado. Por outro lado, o TIAR pode também ser compreendido como parte do projeto pan-americano de estabelecimento de mecanismos de cooperação continental e ação coletiva em diversos campos, aspiração que remonta ao final do século XIX e que só se materializou após a Segunda Guerra Mundial (ROCHA e LE CHAFFOTEC, 2015, p. 4). Nesse caso, o TIAR pode ser enxergado como um instrumento de coordenação das ações individuais dos Estados americanos em casos de ameaça ao continente, parte integrante de uma estrutura mais ampla que abrange diversos mecanismos de cooperação nos campos político, econômico, social e cultural, conforme evidenciado pelo art. $2^{\circ}$ da Carta da OEA.

\section{Medidas QUE PODEM SER ADOTAdas}

A determinação da existência das hipóteses de aplicação do TIAR é o primeiro passo para a adoção de medidas específicas para seu enfrentamento pelo Órgão de Consulta, ${ }^{9}$ que detém

9 O Órgão de Consulta previsto originalmente pelos arts. 11 e 12 do TIAR era a Reunião de Ministros das Relações Exteriores das Repúblicas Americanas ou o Conselho Diretor da União Pan-americana atuando de forma provisória. Com a criação da OEA, esse papel ficou a cargo da Reunião de Ministros das Relações Exteriores da Organização, atuando sob esta designação. 
grande margem de discricionariedade para decidir sobre as ações mais adequadas para lidar com as situações existentes. O TIAR estabelece em seu art. 13 que as medidas a serem tomadas deverão ser decididas em reunião de seu Órgão de Consulta por solicitação de qualquer das partes. Seu art. 20 determina que todas as decisões são obrigatórias para as partes, excetuando medidas que empreguem a força armada.

O rol de medidas que podem ser adotadas pelo Órgão de Consulta do TIAR é estabelecido por seu art. $8^{\circ}$, segundo o qual,

[p]ara os efeitos deste Tratado, as medidas que o órgão de consulta acordar compreenderão uma ou mais das seguintes: a retirada dos chefes de missão; a ruptura de relações diplomáticas; a ruptura de relações consulares; a interrupção parcial ou total das relações econômicas ou das comunicações ferroviárias, marítimas, aéreas, postais, telegráficas, telefônicas, radiotelefônicas ou radiotelegráficas, e o emprego de forças armadas.

Em reuniões realizadas em 23 de setembro e 3 de dezembro de 2019, o Órgão de Consulta aprovou medidas contra membros do governo de Nicolás Maduro e se mostrou disposto a adotar novas ações no futuro. Entre as futuras novas ações que eventualmente podem ser adotadas pelo Órgão estão medidas coercitivas direcionadas a indivíduos ou, em um cenário mais agressivo, medidas que façam uso da força armada.

\section{I. INTERVENÇÃO MILITAR}

A utilização da força armada para a derrubada do regime de Nicolás Maduro é apontada como um dos principais motivos para a adesão da Venezuela ao TIAR feito pela ANV. A ativação do TIAR em conjunto com o art. 187(11) da Constituição Venezuelana - que atribui à ANV o poder de autorizar missões estrangeiras no país - foi aventada por apoiadores de Juan Guaidó e autoridades estrangeiras (FIORELLA, 2019) e alegada pelo governo de Nicolás Maduro (CSNU, 2019), pelo Uruguai (OEA, 2019a) e pelo Panamá (OEA, 2019b).

$\mathrm{O}$ art. $8^{\circ}$ lista de forma indistinta medidas coercitivas que não fazem uso da força, como sanções econômicas e interrupção das relações diplomáticas, e a possibilidade de emprego das forças armadas, sem especificar em quais situações tais medidas podem ser empregadas. A leitura conjunta dos arts. $6^{\circ}$ e $8^{\circ}$ do TIAR inicialmente parece admitir que o emprego de forças armadas seja utilizado ante a existência de uma situação que possa pôr em perigo a paz da América que não configure um ataque armado. Tal interpretação possibilitaria que a ANV solicitasse a intervenção armada dos outros Estados-partes do TIAR para lidar com a situação doméstica no país, já que seus efeitos ultrapassariam suas fronteiras e representariam uma ameaça à paz regional.

No entanto, a inexistência de diferenciação entre as medidas previstas no art. $8^{\circ}$ do TIAR não implica que qualquer uma delas possa ser aplicada a qualquer uma das hipóteses de aplicação do Tratado. Como ressaltado no ponto anterior, o objetivo principal do Tratado 
deve ser levado em conta para a determinação das medidas passíveis de serem empregadas. Dessa forma, o uso da força deve ser empregado apenas na hipótese de exercício da legítima defesa coletiva. De acordo com Josef Kunz:

OTratado do Rio é construído inteiramente sobre o art. 51 da Carta [das Nações Unidas] e sobre a concepção de “ataque armado". Portanto, pode ser apenas um sistema de legítima defesa, não um sistema de sanções. O monopólio do uso da força se encontra nas mãos do Conselho de Segurança; os Estados-membros podem recorrer à força somente nos termos do artigo 51 e somente contra um ataque armado. [...] O Tratado do Rio [...], em consequência de seus fundamentos, nada tem a ver com segurança e sanções coletivas, mas apenas com legítima defesa. (KUNZ, 1948, p. 120, tradução nossa) ${ }^{10}$

A limitação do uso da força também decorre do fato de que o TIAR estabelece em seu art. $1^{\circ}$ a obrigação de suas partes em não utilizarem a força de forma incompatível com a Carta das Nações Unidas, que prevê como únicas exceções à proibição do uso da força a ação autorizada do CSNU e o exercício da legítima defesa coletiva, este último a razão de criação do TIAR. Dessa forma, o emprego de forças armadas previsto no art. $8^{\circ}$ se limita à hipótese de repulsa a um ataque armado contra um Estado americano, estabelecida em seu art. $3^{\circ}$.

Essa leitura é consonante com os trabalhos preparatórios do TIAR. O reconhecimento das duas únicas exceções admitidas pela Carta das Nações Unidas foi ressaltado por sete das oito propostas apresentadas na Conferência Interamericana para a Manutenção da Paz e da Segurança no Continente de 1947 (EUA, 1948, p. 173). ${ }^{11}$

\subsection{MEDIDAS COERCITIVAS QUE NÃO ENVOLVEM O USO DA FORÇA}

O art. $8^{\circ}$ do TIAR se assemelha ao art. 41 da Carta das Nações Unidas, que prevê medidas coercitivas que não envolvem o uso da força que podem ser adotadas pelo CSNU nos casos

10 'The Rio Treaty is built entirely upon Art. 51 of the Charter and on the conception of 'armed attack'. It can, therefore, only be a system of self-defence, not a system of sanctions. The monopoly of the use of force is in the hands of the Security Council; the member-states can resort to force only under Article 51 and only against an armed attack. The Rio Treaty [...] has, in consequence of its basis, nothing to do with collective security and sanctions, but only with self-defence."

11 A Resolução VIII (ou Ato de Chapultepec), aprovada ao final da Conferência Interamericana sobre Problemas da Guerra e da Paz de 1945, que estabeleceu as bases para a criação do TIAR dois anos depois, previa entre as medidas a serem adotadas o "uso da força armada para prevenir ou repelir agressão". A Resolução foi adotada antes da assinatura da Carta das Nações Unidas. 
de ameaça à paz, ruptura da paz ou ato de agressão. ${ }^{12}$ São essas medidas que envolvem o rompimento de relações diplomáticas e consulares, a interrupção de relações econômicas e de transporte, e são conhecidas geralmente como "sanções".

Em sua Resolução de 23 de setembro de 2019, o Órgão de Consulta do TIAR aprovou com base no art. $8^{\circ}$ uma série de medidas a serem tomadas por seus Estados-partes para a identificação de indivíduos ou entidades associados ao governo de Nicolás Maduro envolvidos em lavagem de dinheiro, tráfico ilegal de drogas, terrorismo, financiamento do terrorismo, vinculação a redes transnacionais de crime organizado e corrupção, para posterior investigação, processo e punição destes nos territórios dos Estados-partes do TIAR, de acordo com os sistemas jurídicos domésticos, incluindo o congelamento de seus ativos (parágrafos $1^{\circ}$ e $2^{\circ}$ ). A Resolução também requer a preparação de uma Lista Consolidada de pessoas ligadas a Nicolás Maduro por parte das unidades de inteligência financeira dos Estados (parágrafo $3^{\circ}$ ) e a criação de uma "rede operacional" composta pelos Estados-partes para "intensificar a cooperação legal, judicial e policial” na investigação dos crimes praticados pelos indivíduos e entidades identificados (parágrafo $4^{\circ}$ ).

A Resolução adotada em 3 de dezembro de 2019 determina a ativação de "mecanismos de cooperação e medidas de devida diligência” para o cumprimento da resolução aprovada em 23 de setembro (parágrafo $1^{\circ}$ ) e solicita à "Rede Operacional do TIAR" a definição de parâmetros legais baseados nas legislações domésticas para a inclusão ou exclusão de pessoas da Lista Consolidada (parágrafo $3^{\circ}$ ) e a avaliação da criação de mecanismos de intercâmbio de informações e cooperação com Estados não partes do TIAR que também estipularam sanções à Venezuela (parágrafo $5^{\circ}$ ). A Resolução também solicita aos Estados a criação de medidas de restrição de entrada e trânsito das pessoas incluídas na Lista Consolidada (parágrafo $2^{\circ}$ ). A Lista Consolidada aprovada em 3 de dezembro contém 29 nomes de indivíduos sugeridos por seis países e em sua maioria detentores de cargos de alta hierarquia nos Poderes Executivo e Judiciário da Venezuela, além do próprio Nicolás Maduro e de sua esposa.

As medidas aprovadas pelo Órgão de Consulta são similares às “sanções inteligentes" adotadas pelo CSNU. A lógica de tais sanções se baseia na coerção exercida contra determinadas autoridades e entidades de um Estado e no entendimento de que tais medidas não gerariam efeitos nocivos na população civil, tais como embargos econômicos, como ocorrido no

12 O art. 41 da Carta das Nações Unidas dispõe que: "O Conselho de Segurança decidirá sobre as medidas que, sem envolver o emprego de forças armadas, deverão ser tomadas para tornar efetivas suas decisões e poderá convidar os Membros das Nações Unidas a aplicarem tais medidas. Estas poderão incluir a interrupção completa ou parcial das relações econômicas, dos meios de comunicação ferroviários, marítimos, aéreos, postais, telegráficos, radiofônicos, ou de outra qualquer espécie e o rompimento das relações diplomáticas”. 
Iraque (SALIBA, 2008, p. 74). O congelamento de ativos e a imposição de restrições a viagens de pessoas ou entidades associadas a determinado governo ou grupo armado são medidas características desse tipo de sanção que se tornou prática consolidada da Organização das Nações Unidas (ONU).

Tal como o art. 41 da Carta das Nações Unidas, o art. $8^{\circ}$ do TIAR não admite expressamente a possibilidade de aplicação de sanções inteligentes, que só seriam elaboradas décadas depois da criação de ambos os tratados. Ao contrário da Carta das Nações Unidas, entretanto, não parece haver margem interpretativa no TIAR que possibilite a adoção de sanções que não as tradicionais previstas em seu texto. Isso acontece porque seu art. $8^{\circ}$ estipula que "para os efeitos deste Tratado, as medidas que o órgão de consulta acordar compreenderão uma ou mais das seguintes: [...]", significando que o rol apresentado é exaustivo. O art. 41 da Carta das Nações Unidas, por outro lado, determina que o CSNU “decidirá sobre as medidas que, sem envolver o emprego de forças armadas, deverão ser tomadas para tornar efetivas suas decisões [...] Estas poderão incluir [...]", admitindo que as medidas ali listadas são apenas exemplificativas e que o órgão tem certa margem de discricionariedade para estipular tipos alternativos de sanções (CRETELLA NETO, 2008, p. 642; LAGRANGE e EISEMANN, 2005, p. 1203).

Pode-se argumentar de forma razoável que o congelamento de ativos e as restrições a viagens dos indivíduos listados são medidas que podem ser incluídas no conceito de sanções econômicas e de transporte previstas no art. $8^{\circ}$ do TIAR. Ainda que admitidas pelo Tratado, tais medidas devem ser aplicadas nas hipóteses nele previstas e de acordo com as regras gerais do direito internacional.

No âmbito da Carta das Nações Unidas, a aplicação de sanções pelo CSNU, tal como a autorização do uso da força, só pode ocorrer em razão de ameaças à paz, ruptura da paz ou atos de agressão. Contudo, ao contrário da utilização da força, a Carta não proíbe a aplicação de medidas individualmente por Estados ou de forma concertada fora do âmbito das Nações Unidas, o que a princípio torna lícita a aplicação coletiva de medidas fora do sistema da ONU. ${ }^{13}$ também serão compatíveis com outras obrigações internacionais dos Estados-partes, como obrigações existentes em tratados comerciais. O direito internacional geral admite que sanções econômicas unilaterais podem ser consideradas lícitas se entendidas como contramedidas a determinado ato ilícito internacional, conforme estabelece o art. 22 do Projeto de Artigos sobre a Responsabilidade Internacional dos Estados (2001) da Comissão de Direito Internacional das Nações Unidas. Por outro lado, não é clara no direito internacional a possibilidade de aplicação de contramedidas coletivas contra atos ilícitos internacionais. O art. 54 do Projeto admite a possibilidade de existência de "medidas lícitas" (lawful measures) para a defesa de interesses coletivos dos Estados, mas estabelece que inexiste um direito claramente reconhecido de adoção de tais medidas. 
Esta é a razão pela qual sanções em geral podem ser adotadas no âmbito de organizações regionais sem a prévia autorização do CSNU (DE CHAZOURNES, 2011, p. 266).

OTIAR não estabelece a criação de um sistema regional de segurança coletiva, mas apenas objetiva o estabelecimento de obrigações relativas ao exercício da legítima defesa coletiva, o que faz com que sanções adotadas com base em seus artigos sejam consideradas ilícitas quando não são voltadas ao exercício da legítima defesa ou à repulsa de um ataque armado. O papel de organização regional americana voltada à manutenção da paz e da segurança regionais é exercido pela OEA, que se identifica como um organismo regional integrado ao sistema de segurança coletiva estabelecido pela Carta das Nações Unidas. Apesar de ter sua estrutura utilizada para dar funcionamento ao TIAR, eventuais sanções adotadas pela OEA fora do âmbito do exercício da legítima defesa coletiva devem ter como base jurídica sua Carta, que possui um capítulo específico lidando com a segurança coletiva da América. Sanções econômicas já foram adotadas pela OEA com base em sua Carta contra países como Cuba, Haiti e Panamá, todos Estados-partes do TIAR.

Além das normas do TIAR e da Carta das Nações Unidas, as medidas aprovadas também devem coadunar-se com regras de direitos humanos, em especial o devido processo legal dos indivíduos listados. Desde o julgamento do caso Kadi pelo Tribunal de Justiça da União Europeia em 2008, o respeito aos direitos processuais dos indivíduos incluídos como alvos em listas de sanções de organizações internacionais passou a ser observado de forma mais rigorosa, reconhecendo aos indivíduos o direito ao contraditório e à ampla defesa. A Lista

Consolidada apresentada ao Órgão de Consulta em dezembro de 2019 foi criada sem a estipulação de mecanismos de controle e um quadro jurídico claro que determinasse as regras de inclusão desses indivíduos e procedimentos de retirada, o que encontrou oposição do Panamá.

\section{Conclusão}

Foi motivo de surpresa quando o septuagenário TIAR ganhou manchetes internacionais em 2019. Em parte calcado na lógica do início da Guerra Fria, o Tratado parecia ter sido relegado às páginas da história do direito internacional após ter se mostrado incapaz em 1982 de dar vida ao princípio da solidariedade continental na Guerra das Malvinas (CANÇADO TRINDADE, 1983, p. 259). Desde então cinco de suas 23 partes denunciaram o Tratado, inclusive a Venezuela em 2013.

A readmissão da Venezuela ao TIAR em 2019 levanta não apenas o questionamento em relação à sua utilidade no século XXI, mas também discussões sobre aspectos jurídicos controversos, como a competência da ANV de requisitar o pedido de readmissão e a existência de um direito à intervenção humanitária ou pró-democrática por parte da comunidade internacional que sirva como base jurídica independente para o uso da força contra o território venezuelano. 
Até o momento, a utilização do TIAR no caso concreto da Venezuela não segue a aplicação fiel do texto do instrumento, que não prevê expressamente as hipóteses alegadas para sua utilização ou oferece base jurídica sólida para as medidas já adotadas pelo Órgão de Consulta contra autoridades do país em setembro e dezembro de 2019. Além disso, a aplicação não se coaduna com o objetivo do TIAR de combater ameaças externas que afetem os Estados-membros. Elementos tipicamente alegados no exercício da legítima defesa coletiva, como a existência de grupos armados operando no território venezuelano, têm se misturado a elementos de segurança coletiva regional, como o alegado apoio do governo de Nicolás Maduro a atividades terroristas e a crise humanitária vivenciada pelo país.

Por sua redação imprecisa, o TIAR oferece margens de interpretação que em certa medida são desejáveis em instrumentos do gênero para o enfrentamento de diferentes tipos de ameaça. No entanto, a extrapolação de seus limites hermenêuticos pode levar ao desvirtuamento e a seu enfraquecimento como instrumento de união continental, do qual a recente denúncia do instrumento pelo Uruguai pode ser um efeito.

\section{REFERÊNCIAS}

ARCARI, Maurizio. Il mantenimento della pace e l'uso della forza. In: SCOVAZZI, Tullio (org.). Corso di Diritto Internazionale. 3. ed. Milão: Giuffrè, 2018. p. 195-327.

BROWNLIE, Ian. International Law and the Use of Force by States. Oxford: Oxford University Press, 1963.

CANÇADO TRINDADE, Antonio Augusto. O conflito anglo-argentino no Atlântico Sul e a Vigésima Reunião de Consulta (1982) do Tratado Interamericano de Assistência Recíproca. Revista de Informação Legislativa, Brasília, n. 79, jul./set. 1983.

CASTILlA, Jose Joaquin Caicedo. La Conferencia de Petrópolis y el Tratado Interamericano de Asistencia Recíproca firmado en Río de Janeiro en 1947. Revista de la Universidad Nacional, Bogotá, v. 11, p. 123-208, 1948.

CONSELHO DE SEGURANÇA DAS NAÇÕES UNIDAS (CSNU). Carta de 20 de setembro de 2019 do Representante Permanente da República Bolivariana da Venezuela às Nações Unidas dirigida ao Presidente do Conselho de Segurança, de 23 de setembro de 2019. UN Doc. S/2019/765 (2019).

CONSELHO DE SEGURANÇA DAS NAÇÕES UNIDAS (CSNU). Resolução n. 1373, de 28 de setembro de 2001. UN Doc. S/RES/1373 (2001). 
CORTE INTERNACIONAL DE JUSTIÇA (CIJ). Legal Consequences of the Construction of a Wall in the Occupied Palestinian Territory, Opinião Consultiva de 09 de julho de 2004, ICJ Rep. 2004.

CORTE INTERNACIONAL DE JUSTIÇA (CIJ). Military and Paramilitary Activities in and against Nicaragua (Nicarágua v. Estados Unidos da América), Méritos, julgamento de 27 de junho de 1986, ICJ Rep. 1986.

CORTEN, Olivier. The Law against War: The Prohibition on the Use of Force in Contemporary International Law. Oxford: Hart Publishing, 2010.

CRETELLA NETO, José. Artigo 41. In: BRANT, Leonardo Nemer Caldeira (org.). Comentário à Carta das Nações Unidas. Belo Horizonte: CEDIN, 2008. p. 625-654.

DE CHAZOURNES, Laurence Boisson. Les relations entre organisations régionales et organisations universelles. Recueil des Cours de l'Académie de Droit International de La Haye, Leiden, v. 347, p. 100-406, 2011.

ESTADOS UNIDOS DA AMÉRICA (EUA). Department of State. Inter-American Conference for the Maintenance of Continental Peace and Security (Quitandinha, Brazil, August 15-September 2, 1947), Report of the Delegation of the United States of America. Washington: Government Printing Office, 1948.

FIORELLA, Giancarlo. Will Guaidó Call for U.S. Military Intervention? Venezuela's Debate Over Article 187(11), Foreign Affairs, 17 abr. 2019. Disponível em: https://www.foreignaffairs.com/ articles/venezuela/2019-04-17/will-guaido-call-us-military-intervention. Acesso em: 10 dez. 2019.

GARCIA-MORA, Manuel. The Law of the Inter-American Treaty of Reciprocal Assistance. Fordham Law Review, Nova York, v. 20, n. 1, p. 1-22, 1951.

KUNZ, Josef. The Inter-American Treaty of Reciprocal Assistance. American Journal of International Law, Washington D.C., v. 42, n. 1, p. 111-120, jan. 1948.

LAGRANGE, Evelyne; EISEMANN, Pierre Michel. Article 41. In: COT, Jean-Pierre; PELLET, Alain; FORTEAU, Mathias (org.). La Charte des Nations Unies: commentaire article par article. 3. ed. Paris: Economica, 2005. p. 1195-1242.

LIMA, Lucas Carlos. O Comitê Jurídico Interamericano da OEA e a codificação do direito internacional regional. Revista de Direito Internacional, Brasília, v. 16, n. 2, p. 292-302, 2019.

MINISTÉRIO DAS RELAÇÕES EXTERIORES (MRE). Declaração do Grupo de Lima em apoio ao processo de transição democrática e à reconstrução da Venezuela (Bogotá, 25 de fevereiro de 2019), 27 fev. 2019. 
Disponível em: https://www.gov.br/mre/pt-br/canais_atendimento/imprensa/notas-a-imprensa/ 2019/declaracao-do-grupo-de-lima-em-apoio-ao-processo-de-transicao-democratica-e-a-reconstrucaoda-venezuela-bogota-25-de-fevereiro-de-2019. Acesso em: 10 dez. 2019.

ORGANIZAÇÃO DAS NAÇÕES UNIDAS (ONU). Carta da Organização dos Estados Americanos (emendada pelo Protocolo de Reforma de 27 de fevereiro de 1967). United Nations Treaty Series, v. 721, p. 324, 1974.

ORGANIZAÇÃO DAS NAÇÕES UNIDAS (ONU). Tratado Interamericano de Assistência Recíproca, Rio de Janeiro, 2 set. 1947. United Nations Treaty Series, v. 21, p. 77, 1948.

ORGANIZAÇÃO DAS NAÇÕES UNIDAS (ONU). Carta das Nações Unidas, São Francisco, 26 jun. 1945.

ORGANIZAÇÃO DOS ESTADOS AMERICANOS (OEA). 30a Reunião de Consulta dos Ministros das Relações Exteriores. Resolução n. 1, RC.30/RES. 1/19, 23 de setembro de 2019a.

ORGANIZAÇÃO DOS ESTADOS AMERICANOS (OEA). 30ª Reunião de Consulta dos Ministros das Relações Exteriores. Resolução n. 2 (A crise na República Bolivariana da Venezuela e seus efeitos desestabilizadores no Hemisfério), RC.30/RES. 2/19, 3 de dezembro de 2019b.

ORGANIZAÇÃO DOS ESTADOS AMERICANOS (OEA). $20^{a}$ Reunião de Consulta dos Ministros das Relações Exteriores. Resolução n. 1 (Grave situação criada no Atlântico Sul), OEA/Ser.F/II.20, Doc. 28/82, 28 de abril de 1982.

ORGANIZAÇÃO DOS ESTADOS AMERICANOS (OEA). $18^{a}$ Reunião de Consulta dos Ministros das Relações Exteriores. Resolução sobre a situação existente entre Costa Rica e Nicarágua, CP/RES. 262 (362/78), 30 de dezembro de 1978.

ORGANIZAÇÃO DOS ESTADOS AMERICANOS (OEA). $8^{a}$ Reunião de Consulta dos Ministros das Relações Exteriores. Resolução n. 1 (Ofensiva do comunismo na América), OEA/Ser.C/II.8, 22 a 31 de janeiro de 1962a.

ORGANIZAÇÃO DOS ESTADOS AMERICANOS (OEA). $8^{a}$ Reunião de Consulta dos Ministros das Relações Exteriores. Resolução n. 2 (Comitê Consultivo Especial sobre Segurança contra a ação subversiva do comunismo internacional), OEA/Ser.C/II.8, 22 a 31 de janeiro de 1962b.

ORGANIZAÇÃO DOS ESTADOS AMERICANOS (OEA). $8^{a}$ Reunião de Consulta dos Ministros das Relações Exteriores. Resolução n. 3 (Reiteração dos princípios da não intervenção e autodeterminação), OEA/ Ser.C/II.8, 22 a 31 de janeiro de 1962c. 
ORGANIZAÇÃO DOS ESTADOS AMERICANOS (OEA). 6 a Reunião de Consulta dos Ministros das Relações Exteriores. Resolução n. 1, OEA/Ser.C/I, 21 de agosto de 1960.

RATNER, Steven. Self-Defence against Terrorists: The Meaning of Armed Attack. In: VAN DER HERIK, Larissa; SCHRIJVER, Nico. Counter-Terrorism Strategies in a Fragmented International Legal Order: Meeting the Challenges. Cambridge: Cambridge University Press, 2013. p. 334-355.

REUTERS. Venezuela Rejoins Regional Defense Treaty but Guaidó Warns it’s no “Magic”Solution, 23 jul. 2019. Disponível em: https: / /www.reuters.com/article/us-venezuela-politics/venezuela-rejoins-regionaldefense-treaty-but-guaido-warns-its-no-magic-solution-idUSKCN1UI2JX. Acesso em: 10 dez. 2019.

ROCHA, Alexandre Moreli; LE CHAFFOTEC, Boris. Countering War or Embracing Peace? Dialogues between Regionalism and Multilateralism in Latin America (1945-1954). Culture \& History Digital Journal, Madri, v. 4, n. 1, p. 1-10, 2015.

SALIBA, Aziz Tuffi. Conselho de Segurança: sanções e limites jurídicos. Curitiba: Juruá, 2008.

STROMSEHT, Jane; BROOKS, Rosa;WIPPMAN, David. Can Might Make Rights? Building the Rule of Law after Military Interventions. Cambridge: Cambridge University Press, 2006.

VENEZUELA. Asamblea Nacional de la República Bolivariana de Venezuela. Exposición de Motivos Ley aprobatoria de adhesión al "Tratado Interamericano de Asistencia Recíproca (TIAR), suscrito en la ciudad de Río de Janeiro - Brasil en 2 de septiembre de 1947; así como su Protocolo de Reforma, de San José de Costa Rica, firmado el 26 de Julio de 1975”. Gaceta Legislativa, n. 10, 14 ago. 2019. Disponível em: https: / / asambleanacional-media.s3.amazonaws.com/documentos/gaceta/gaceta_ 1570197827.pdf. Acesso em: 12 dez. 2019.

\section{COMO CITAR ESTE ARTIGO:}

CAMPOS, Bernardo Mageste Castelar. A aplicação do Tratado Interamericano de Assistência Recíproca (TIAR) à crise venezuelana de 2019. Revista Direito GV, São Paulo,v. 18, n. 1, jan./abr. 2022, e2203. https://doi.org/10.1590/23176172202203

\section{Bernardo Mageste Castelar Campos}

Doutorando EM DIREITO INTERNACIONAL NA UNIVERSITÀ DEGLI Studi di Milano-Bicocca (Itália). Mestre em Direito InTERnaCIONAL Contemporâneo PELA UnIVERsidade FEdERAL de Minas Gerais (UFMG).

bernardo.magestelamail.com 